\section{Soviet psychiatry}

\section{Mock trial in London}

THE second anniversary of the arrest in the Soviet Union of Alexandr Podrabinek was marked in London last week (15 May) by a "public hearing" on the alleged abuse of psychiatry in the Soviet Union. Podrabinek is the author of the samizdat treatise "Punitive Medicine" and a member of the organisation known by the cumbersome title of Working Commission for the Investigation of the Misuse of Psychiatry for Political Purposes.

The chief object of last week's hearing, at which Mr Louis Blom-Cooper Q.C. put the case for the prosecution, was to draw attention to the plight of the working commission, only two of whose original members remain at liberty in the Soviet Union. Other members of the commission now arrested include the mathematician Vyacheslav Bahkmin (12 February, 1980) and the physician Leonard Tarnovskii (4 April, 1980). The pharmacist Viktor
Nekipelov, who was a member of the Moscow Helsinki Monitoring Group, had worked closely with the commission until his arrest on 7 December last year.

At last week's proceedings, one of the chief witnesses was Dr Alexandr Voloshanovich, who had been forced to emigrate to Britain in February this year. He told the hearing that he had investigated a total of forty alleged victims of psychiatric abuse before his departure from the Soviet Union, but that in no case had he found "indisputable evidence of the need for hospitalization".

Interest in the West has necessarily centred on the more spectacular cases of alleged psychiatric abuse, such as the hospitalization of Petro Grigorenko for his defence of the Crimean Tartars (and whose cases was simulated in last week's mock trial). Dr Voloshanovich emphasised, however, that the cases which he had investi- gated were varied, and that in his experience some of those sent to psychiatric hospitals had not given political offence but, rather, had simply been troublemakers for the system.

Mr Peter Reddaway, co-author of the book "Russia's Political Hospitals", sug. gested that psychiatric abuse has featured "quite prominently" in recent arrests of those known to have dissident sympathies. Of 200 arrested since last autumn, he said, fifteen have ended up in psychiatric hospitals.

Even so, there are some signs that the Soviet authorities are sensitive to allegations of the misuse of psychiatry in the Soviet Union. When the Royal College of Psychiatrists (London) wrote at the beginning of the year to Dr Andrei Snezhnevskii asking for an explanation of the growing number of reports of psychiatric abuse in the Soviet Union, Snezhnevskii offered no explanation but did resign his honorary membership of the college.

Vera Rich

\title{
Antarctic ecology
}

\section{Monitoring krill from land}

THIS season's Polish expedition to the Antarctic returned home two weeks ago claiming that it should at some stage be possible to monitor the exploitation of Antarctic krill by observation of the landbased fauna of the Antarctic coast. This is one of the arguments that Polish ecologists will be putting to the forthcoming conference in Paris on Antarctic biomass.

The Polish Antarctic base "Henryk Arctowski" was established in 1976 on King George Island in the South Shetland Islands and can accommodate 70 people in summer, with up to twenty people over-wintering. Given the location of the station, Polish concern with the oceanic ecology of the Antarctic is understandable.

Dr Stansilaw Rakusa-Suszczewski, of the Polish Institute of Ecology and coordinator of the biological part of the Antarctic programme, said after the expedition had returned that Poland has no ambition to exploit Arctic krill commercially, but that for the time being at least is concerned only to understand more clearly the somewhat fragile ecology of the Antarctic.

The chief objectives of the biological part of the past season's Antarctic programme were to understand the flow of nutrients off the coast of Antarctica in such detail that marine production could be accounted for. Previous Polish expeditions to the Antarctic have drawn attention in their reports to the way in which marine production is determined jointly by off-shore upwelling and the ex- change of material between the sea and land surfaces.

Dr Rakusa-Suszczewski now thinks that it will in due course be possible to follow the production and exploitation of oceanic krill, and of other marine animals occupying lowly positions in the foodchain - almost literally low in the oceanic pecking order - simply by mainaining regular counts of the populations of penguins and seals living on the Antarctic coastline.

Marine ecologists will no doubt await the publication of the past season's results before accepting Dr RakusaSuszczewski's claim. Penguins and seals are known to be in-shore feeders, and the dependence on what happens in the deep

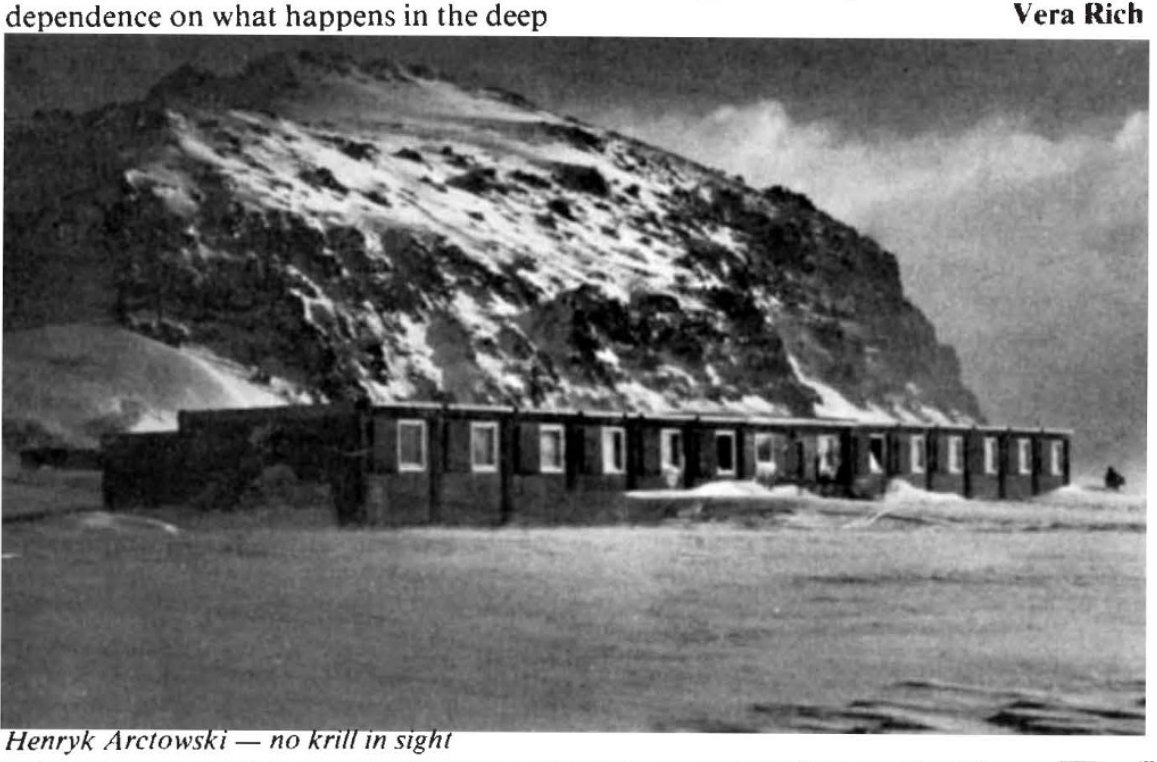

Antarctic must be tenuous, to say the least of it.

Nevertheless, in strict compliance with the formal terms of science planning in Poland, the Antarctic programme of research is aimed at the solution of an "interdepartmental problem", defined as such because it integrates "environmental and biological research with the objective of understanding the dependence and functioning of part of the ecosystem and the inflow of material in the inshore zone of Admiralty Bay'”.

In case all the subtleties of Antarctic ecology can be worked out only after further painstaking research, Dr RakusaSuszczewski is also at pains to emphasise that the past season has produced some practical benefits - the possibility that fish-bile may be a valuable source of cholic acid for the pharmaceutical industry, for example.

Henryk Arctowski - no krill in sight 